\title{
Obstructive Sleep Apnea as the Initial Manifestation of Acromegaly
}

\author{
${ }^{1}$ A Ghabeli Joubari, ${ }^{2}$ Fariborz R Talab, ${ }^{3} \mathrm{M}$ Akbari Rad, ${ }^{4}$ Abdollah Firoozi, ${ }^{5}$ Fariba Rezaeetalab
}

\begin{abstract}
Obstructive sleep apnea syndrome (OSAS) is the most common type of sleep disorder, a chronic condition characterized by frequent episodes of upper airway obstruction during sleep. There are serious complications associated with this condition, varying from different respiratory complications, neuropsychiatric disturbances to increased risk of hypertension and cardiovascular disorders. The OSAS frequently occurs in acromegaly patients with a high prevalence rate of 20 to $50 \%$. The symptoms of sleep apnea, including snoring, tiredness, and excessive daytime sleepiness, are often reversible with an appropriate treatment strategy. We report here a middle-aged woman with excessive snoring and severe headaches caused by sleep apnea as a first sign, years before definite diagnosis of acromegaly.
\end{abstract}

Keywords: Acromegaly, Sleep apnea, Sleep-disordered breathing.

How to cite this article: Joubari AG, Talab FR, Rad MA, Firoozi A, Rezaeetalab F. Obstructive Sleep Apnea as the Initial Manifestation of Acromegaly. Indian Sleep Med 2017;12(2):21-23.

Source of support: Nil

Conflict of interest: None

\section{CASE REPORT}

A 46-year-old married woman referred with symptoms of headache, snoring, and daytime sleepiness. She had reported a history of hypertension for previous 4 years.

\footnotetext{
${ }^{1}$ Neurologist, ${ }^{2,3}$ Assistant Professor, ${ }^{4}$ Pharmacist, ${ }^{5}$ Associate Professor

${ }^{1}$ Department of Neurology, Shahid Motahhari, Educational Hospital, Shiraz, Islamic Republic of Iran; University of Medical Sciences, Marvdasht, Islamic Republic of Iran
}

${ }^{2}$ Department of Neurology, School of Medicine, Mashhad University of Medical Sciences, Mashhad, Islamic Republic of Iran

${ }^{3}$ Department of Toxicology, Mashhad University of Medical Sciences, Mashhad, Islamic Republic of Iran

${ }^{4}$ Lung Disease Research Center, Mashhad University of Medical Sciences, Mashhad, Islamic Republic of Iran

${ }^{5}$ Department of Pulmonology, Lung Disease Research Center Mashhad University of Medical Sciences, Mashhad, Islamic Republic of Iran

Corresponding Author: Fariba Rezaeetalab, Associate Professor, Department of Pulmonology, Lung Disease Research Center, Mashhad University of Medical Sciences, Mashhad, Islamic Republic of Iran, Phone: +00989155033468, e-mail: rezaitalabf@mums.ac.ir
Head and neck, abdominal, extremities, lung and heart examinations were normal, her body mass index (BMI) was $25 \mathrm{~kg} / \mathrm{m}^{2}$, and her neck circumference was $37.5 \mathrm{~cm}$. Cranial nerve examination shown no abnormality. As sleep-disordered breathing was suspected, a polysomnography was conducted. By applying polysomnographic data (Fig. 1), the diagnosis of severe obstructive sleep apnea (OSA) was confirmed, and continuous positive airway pressure (CPAP) machine was administered for her condition. Two years later, she noticed a nodule in her neck. Further examinations showed a multinodular goiter. She afterward underwent for nodule resection surgery that was benign in pathology. Four years later she noticed facial changes which she thought was related to CPAP mask. Consequently, she experienced narrowing shoes and tightness of ring, change of voice tone along with numbness and tingling sensation in both hands. No significant past or family history of endocrine disorders was reported. Additional examinations showed elongated head, prominent supraorbital ridges, and enlarged extremities, nose, lips, and ears. A blood test reported fasting blood sugar $=120 \mathrm{mg} / \mathrm{dL}$, prolactin $=80 \mathrm{ng} / \mathrm{mL}$ (normal $=$ up to $20 \mathrm{ng} / \mathrm{mL}$ ), insulin-like growth factor $1=633 \mu \mathrm{g} / \mathrm{L}$ $($ normal $=$ up to $250 \mu \mathrm{g} / \mathrm{L})$, growth hormone $($ basal $)=$ $39 \mathrm{ng} / \mathrm{mL}$ (normal = less than $10 \mathrm{ng} / \mathrm{mL}$ ), oral glucose tolerance test (OGGT) (1 hour after administration of $100 \mathrm{gm}$ oral glucose $)=19.4 \mathrm{ng} / \mathrm{mL}$, OGGT ( 2 hours after administration of $100 \mathrm{gm}$ oral glucose) $=51 \mathrm{ng} / \mathrm{mL}$. Her MRI showed a tumoral lesion in hypophysis of brain (Fig. 2).

\section{DISCUSSION}

The OSAS is a common disorder especially in obese adults characterized by recurrent episodes of apnea and hypopnea during the sleep. Total or partial collapse of the pharynges and upper airways due to changes in the soft tissue and the shape or size of the related bone and cartilage is the main cause of sleep apneas. ${ }^{1-3}$ Such abnormalities may occur as a well-known result of acromegaly. The incidence of OSAS is 0.8 to $2.8 \%$ in children and 2 to $26 \%$ in adults (different races and populations). This condition is more common in obese adults with an incidence rate of 39 to $71 \%$ compared with adults with normal BMI. ${ }^{2,4}$ The OSAS may cause many different complications varying from oxygen desaturation, negative intrathoracic pressure, upper airway obstructions alone or with aerosol 


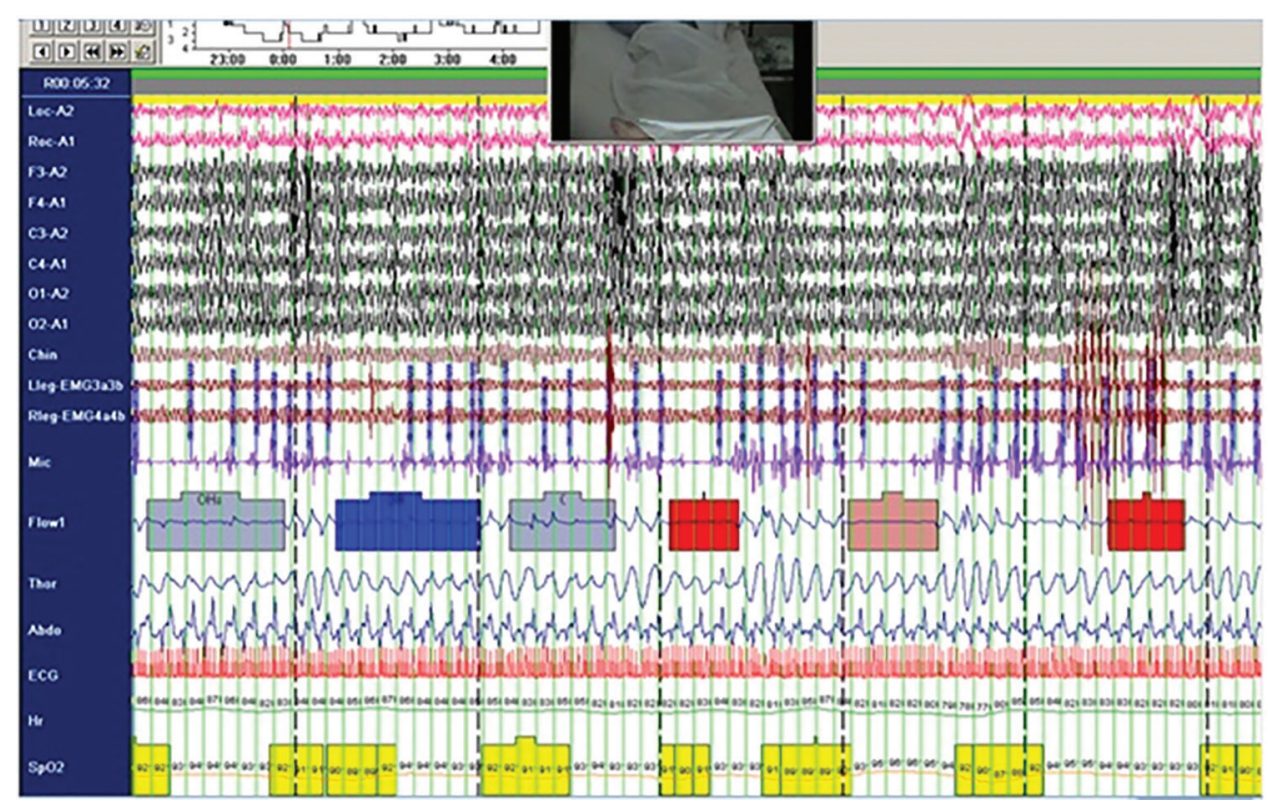

Fig. 1: Polysomnography illustrated OSA
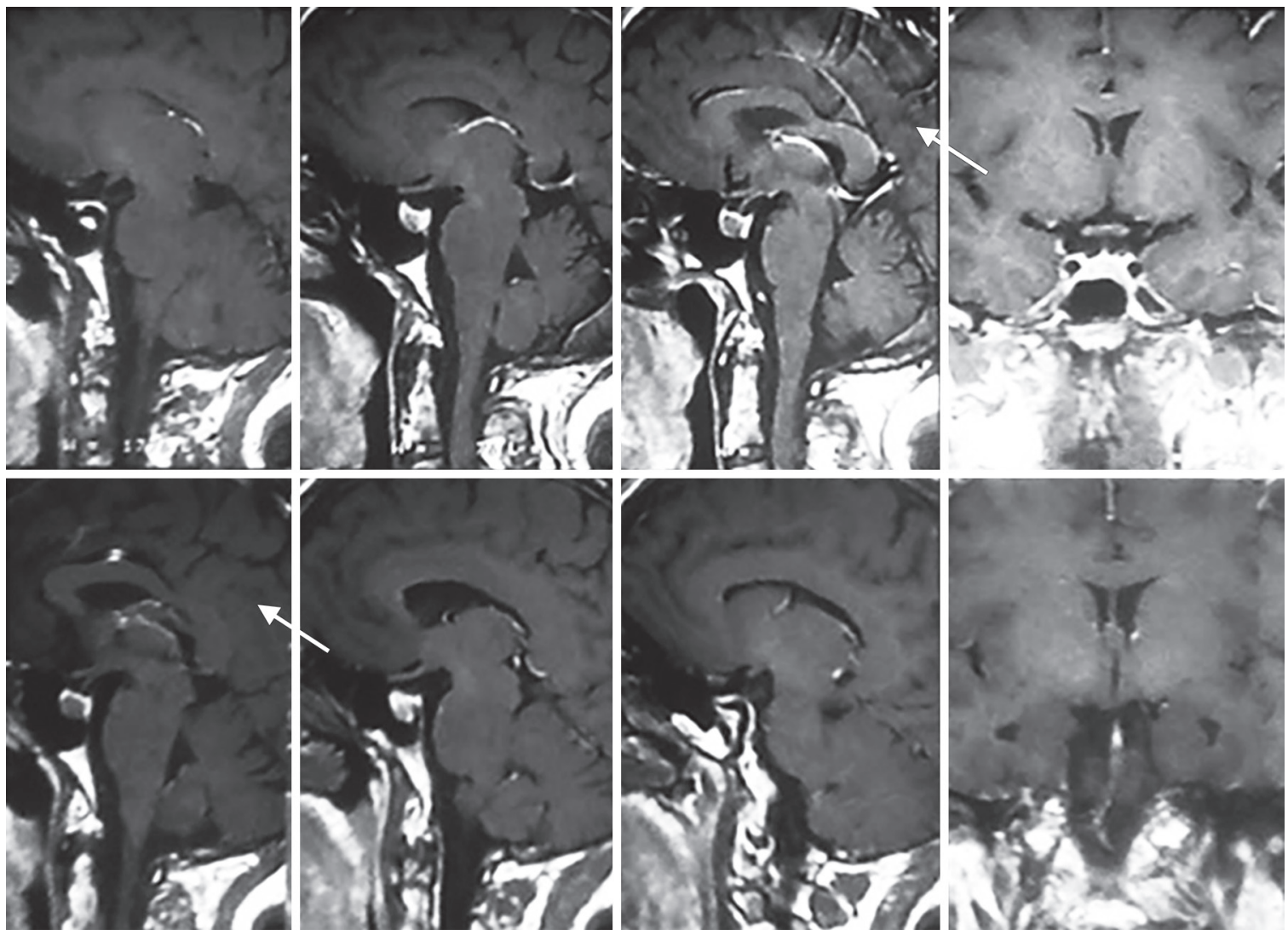

Fig. 2: Sagittal (right) gadolinium-enhanced T1-weighted MRI images. There was a well-defined mass seen with the size of $12 \times 8 \mathrm{~mm}$ in the center of pituitary gland without stalk shift that is not getting enhanced after injection of contrast agent. It is more likely to be Rathke cyst. Dynamic MRI is more accurate and recommended

involvement, and repeated activation of sympathetic system that may cause activation of neural, humoral, metabolic, thrombotic, and many cases of inflammation and immune system activation that leads to atherosclerosis, hypertension, cardiovascular and cerebrovascular conditions, and increased risk of sudden death. ${ }^{5-7}$
Acromegaly is a disease resulting from excessive production of growth hormone $(\mathrm{GH})$ and insulin-like growth factor type I (IGF-1) that in most cases are related to pituitary adenoma. Its prevalence is estimated around 0.3 to 0.4 per 100,000 per year. Acromegaly is characterized by slowly progressive deformities mostly in the face and 
extremities. ${ }^{8,9}$ Because gradual changes in clinical signs of acromegaly, lead to a definitive diagnosis is delayed. There are many different disorders related to acromegaly including cardiovascular, rheumatologic, respiratory and metabolic involvements, and sleep disorders.

Ten years after the first introduction of acromegaly (1896), Roxburgh and Collins reported a patient who had acromegaly and suffered from daytime somnolence and sleeping spells, the symptoms of OSA. ${ }^{10}$ Nowadays OSAS is considered as a common disorder in acromegaly patients with a high prevalence rate. This condition increases the risk of cardiovascular complications in patients. The main reasons that increase the incidence rate of OSAS in acromegaly patients are deformities in craniofacial bones, hypertrophy of pharyngeal soft tissue, and mucosal thickening of the upper airways and bronchi. ${ }^{11}$ There is a positive correlation reported between the incidence of OSA and GH/IGF-1 index in acromegaly patients. ${ }^{12-14}$ The OSA is more common in acromegaly patients who are male, elderly, have higher $\mathrm{BMI}$ and neck circumference and tongue size with greater duration of disease. ${ }^{11,13,14}$

Our reported patient had undergone transsphenoidal surgery. Afterward, we had prescribed somatostatin analog for her.

\section{CONCLUSION}

In OSA patients, it is recommended to conduct a precise evaluation and close follow-up, by which a specific etiology like acromegaly may be discovered.

\section{REFERENCES}

1. Correa Cde C, Blasca WQ, Berretin-Felix G. Health promotion in obstructive sleep apnea syndrome. Int Arch Otorhinolaryngol 2015 Apr;19(2):166-170.

2. Archontogeorgis K, Nena E, Papanas N, Steiropoulos P. Biomarkers to improve diagnosis and monitoring of obstruc- tive sleep apnea syndrome: current status and future perspectives. Pulm Med 2014;2014:930535.

3. Attal P, Chanson P. Endocrine aspects of obstructive sleep apnea. J Clin Endocrinol Metab 2010 Feb;95(2):483-495.

4. Wang P, Yu DJ, Feng G, Long ZH, Liu CJ, Li H, Zhao TL. Is floppy eyelid syndrome more prevalent in obstructive sleep apnea syndrome patients? J Ophthalmol 2016;2016:6980281.

5. Stiefel P, Sanchez-Armengol MA, Villar J, Vallejo-Vaz A, Moreno-Luna R, Capote F. Obstructive sleep apnea syndrome, vascular pathology, endothelial function and endothelial cells and circulating microparticles. Arch Med Res 2013 Aug;44(6):409-414.

6. Shamsuzzaman AS, Gersh BJ, Somers VK. Obstructive sleep apnea: implications for cardiac and vascular disease. JAMA 2003 Oct 8;290(14):1906-1914.

7. Eisensehr I, Ehrenberg BL, Noachtar S, Korbett K, Byrne A, McAuley A, Palabrica T. Platelet activation, epinephrine, and blood pressure in obstructive sleep apnea syndrome. Neurology 1998 Jul;51(1):188-195.

8. Chanson P, Salenave S, Kamenicky P, Cazabat L, Young J. Pituitary tumours: acromegaly. Best Pract Res Clin Endocrinol Metab 2009 Oct;23(5):555-574.

9. Hernandez-Gordillo D, Ortega-Gomez Mdel R, Galicia-Polo L, Castorena-Maldonado A, Vergara-Lopez A, GuillenGonzalez MA, Torre-Bouscoulet L. Sleep apnea in patients with acromegaly. Frequency, characterization and positive pressure titration. Open Respir Med J 2012;6:28-33.

10. Barkan A. Acromegalic arthropathy and sleep apnea. J Endocrinol 1997 Oct;155 (Suppl 1):S41-S44; discussion S45.

11. Davi MV, Dalle Carbonare L, Giustina A, Ferrari M, Frigo A, Lo Cascio V, Francia G. Sleep apnoea syndrome is highly prevalent in acromegaly and only partially reversible after biochemical control of the disease. Eur J Endocrinol 2008 Nov;159(5):533-540.

12. Pekkarinen T, Partinen M, Pelkonen R, Iivanainen M. Sleep apnoea and daytime sleepiness in acromegaly: relationship to endocrinological factors. Clin Endocrinol (Oxf) 1987 Dec;27(6):649-654.

13. Perks WH, Horrocks PM, Cooper RA, Bradbury S, Allen A, Baldock N, Prowse K, van't Hoff W. Sleep apnoea in acromegaly. Br Med J 1980 Mar 29;280(6218):894-897.

14. Hart TB, Radow SK, Blackard WG, Tucker HS, Cooper KR. Sleep apnea in active acromegaly. Arch Intern Med 1985 May;145(5):865-866. 